
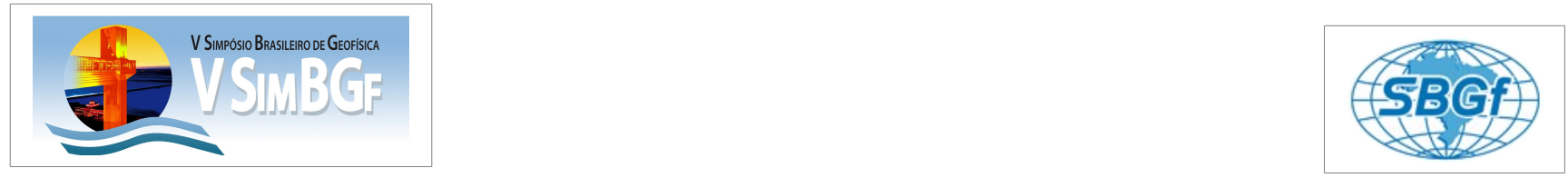

\title{
Macrossismos virtual para apoio a Sismicidade Brasilieira
}

Juliana Garrido Damaceno, Observatório Sismológico, Instituto de Geociências, UnB George Sand França, Observatório Sismológico, Instituto de Geociências, UnB

Isadora Maia Sousa, Observatório Sismológico, Instituto de Geociências, UnB

Copyright 2012, SBGf - Sociedade Brasileira de Geofísica

Este texto foi preparado para a apresentação no V Simpósio Brasileiro de Geofísica, Salvador, 27 a 29 de novembro de 2012. Seu conteúdo foi revisado pelo Comitê Técnico do V SimBGf, mas não necessariamente representa a opinião da SBGf ou de seus associados. É proibida a reprodução total ou parcial deste material para propósitos comerciais sem prévia autorização da SBGf.

\section{Abstract}

Until now, Brazil there is no database of information macroseismic, which are limited to each seismological center. This job seek to establish or enhance the system of information macroseismic database, initially by the internet. The result of this paper presents maps with information regarding the magnitude and seismic intensity.

\section{Introdução}

Com o avanço da tecnologia, a comunicação foi facilitada e relatos de eventos sísmicos são quase que instantaneamente noticiados pela população por meio da internet, e, mesmo em locais onde não possuam uma rede de monitoramento de estações sismográficas, é possível o estudo por relatos que são chamados de dados macrossísmicos e correspondem a sensação nas pessoas, queda de objetos, rachaduras em paredes, desabamentos de casas.

Objetivamos classificar esses dados macrossísmicos e auxiliar no mapa da sismicidade brasileira com reforço da intensidade sísmica. O Brasil, ao contrário do que muitos acreditam, não possui apenas sismicidade resultante da atividade das bordas litosféricas, mas existe uma dinâmica intraplaca, que não é tão intensa ou frequente, porém deve ser considerada, pois os resultados são visíveis, causam danos materiais e pânico na população. Uma das regiões brasileiras mais ativas é o Nordeste (Berrocal et al. 1984, França 2005), principalmente nos estados do Ceará, Rio Grande do Norte e Pernambuco, nestes locais o governo já lançou cartilhas informativas alertando os habitantes, mas em algumas localidades a população preferiu se retirar do local com medo da pouca estrutura de suas casas. Os tremores mais fortes registrados no Brasil ocorreram em regiões pouco habitadas na época, porém com a expansão sem planejamento dos centros urbanos, aumenta o risco de desastres em caso de tremor de terra. No caso de usinas nucleares e hidroelétricas, é obrigatório o monitoramento destes locais, mas não deve se limitar a elas o estudo geofísico. Recentemente, o Brasil vem se estabelecendo com uma grande rede sismográficas, no entanto não se deve negar a importância dos dados microssísmicos para um acompanhamento mais detalhado da sismicidade. Orientar a população dos locais de maior ocorrência a se protegerem, bem como estimulá-la a construir casas mais seguras, deve ser como regra para defesa civil. O único caso de vítima fatal pro terremoto, foi de uma criança de 5 anos em Caraíbas, no município de Itacarambi, no Norte de Minas Gerais em dezembro de 2007 (Chimpliganond et al. 2010). Outro caso marcante ocorreu na cidade de João Câmara-RN, em que 4000 casa foram danificadas.

\section{Coleta de Dados}

Os dados coletados foram a partir de agosto de 2007, que foram divulgados pela internet através dos jornais online, blogs, twitters com o efeito no território brasileiro. Usamos artifícios, tais como, google alerts para auxiliar nesse trabalho. Os eventos foram selecionados por: andinos, locais, explosão/desabamento ou outros, caso haja uma estação sismográfica próxima a região que tenha captado o tremor, a magnitude será informada e a Escala de Mercalli Modificada, mais subjetiva, foi feita com base nos relatos da população. Foram um total de 200 eventos notificados, com média de 4 notificações por mês (Figura 1). Eventos sem informação de magnitude e duvidoso fora notificados com magnitude Zero.

Alguns eventos andinos que foram sentidos pela população também foram inseridos no banco de dados macrosísmicos.

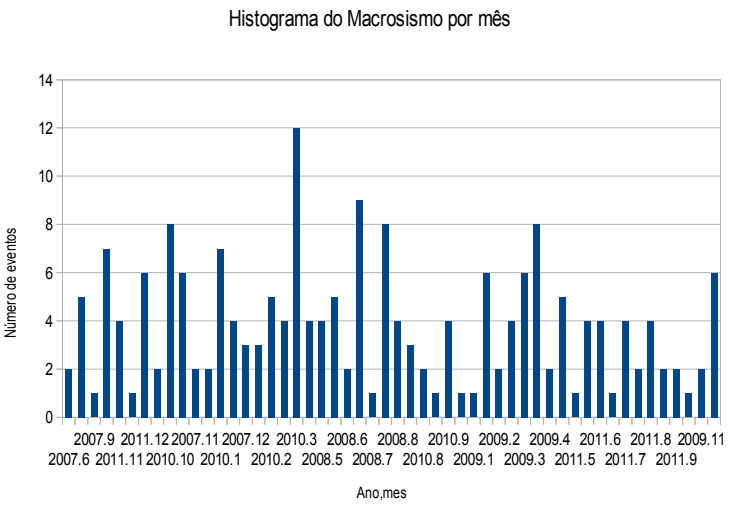

Figura 1 - Histograma - Números de eventos versus ano.mês

\section{Resultados e Discussões}

Com essas informações, foi gerado dois mapas de macrosismo usando informações on-line, separado por magnitude e intensidade (Figura 2) e uma planilha com colunas ano, mes, dia, horário próvavel, magnitude, intensidade, cidade, fontes, observações. Já existe um arquivo texto por ano disponíveis no blog tremordeterra.blogspot.com, entretanto o próximo passo 
é deixar esses dados em banco de dados em diversos formatos. Também intengrar os diversos orgãos para completar o banco de dados.

A importancia do Macrosismo "Virtual" é somar com banco de dados de macrosismo brasileiro inexistente principalmente em áreas que não temos acessos e também auxiliar os analista em diversas partes do país para certificar eventos mencionados pela população. Como exemplo, o evento no dia 30 julho de 2010 em Jaragua do Sul-SC, não registrados pela estações sismográficas instaladas pelo pais.

\section{Agradecimentos}

Ao CNPq pelo apoio concedido através $\mathrm{PQ}$, ao meios de comunicação que possibilita esse trabalho

\section{Referências}

Berrocal, J., Assumpção, M. S., Antezana, R., Dias Neto, C. M., Ortega, R., Franca, H., Veloso, J. A. V. 1984. Sismicidade do Brasil. Instituto Astronómico e Geofísico, São Paulo, Brasil, 320p

Chimpliganond, C., Assumpção, M., Von Huelsen, M., França, G. S., 2010. The intracratonic Caraíbas Itacarambi earthquake of December 09, 2007 (4.9 mb), Minas Gerais State. Journal of Geophysical Research.

França, G. S. 2006. Brazil Seismicity. Bulletin of the International Institute of Seismology and Earthquake Engineering, Japão, v. 40, p. 23-36.
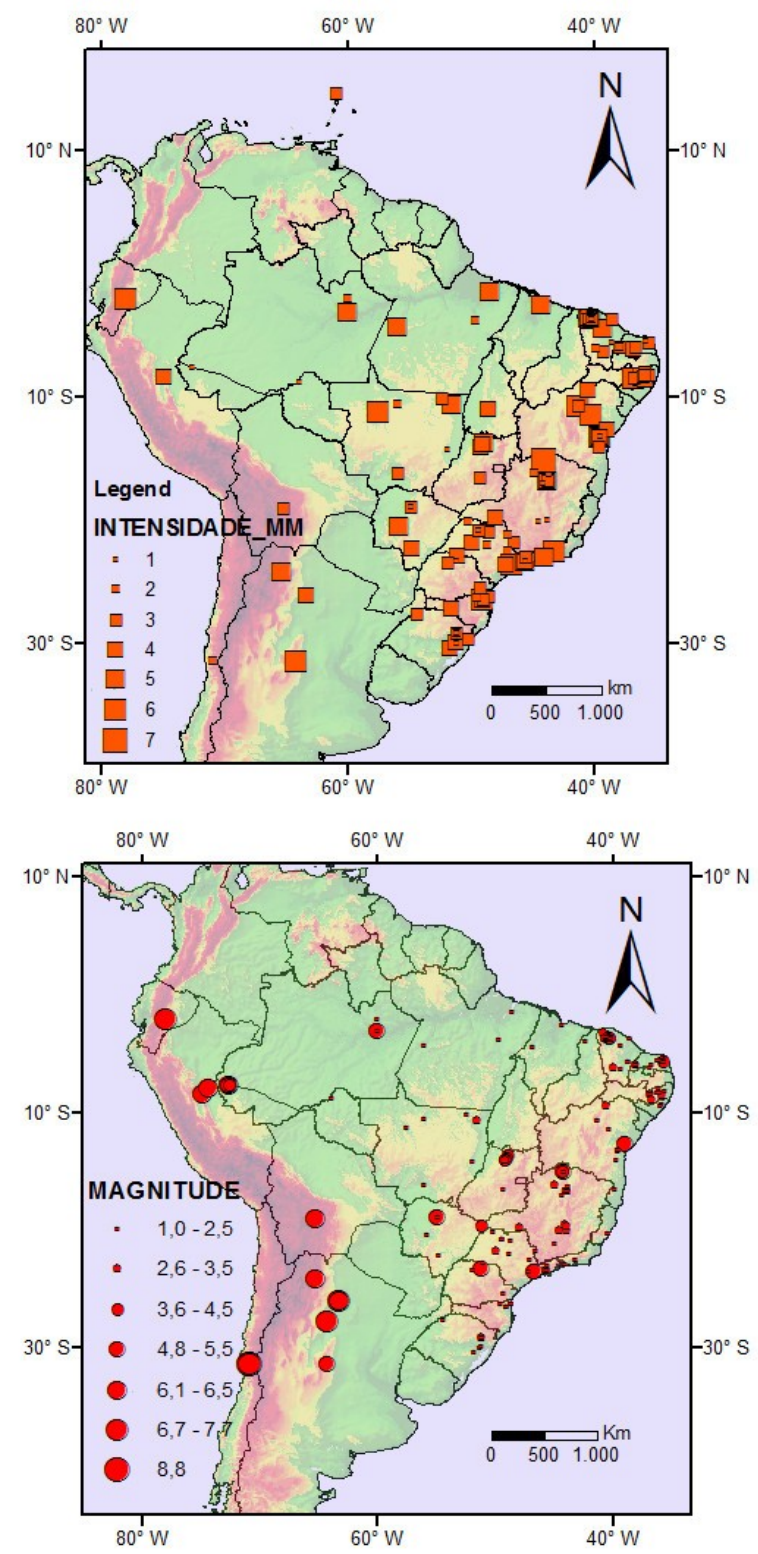

Figura 2 - Acima - Mapa de Macrosismo com Intensidade 2007-2011 e Abaixo: Mapa de Macrosismo com Magnitude 2007-2011. 